\title{
La historia de la humanidad interpretada de manera humanista ${ }^{1}$
}

\section{The history of humanity interpreted in a humanistic $w a y^{2}$}

Michele Borrelli ${ }^{3}$

Universitá della Calabria, Italia

Recepción: 25 de octubre del 2020

Evaluación: 19 de noviembre del 2020

Aceptación: 20 de noviembre del 2020

1 Este artículo fue realizado en el marco del trabajo investigativo llevado a cabo en la Universitá della Calabria (Italia).

2 Traducción del alemán por Mikhail Krasnov, Instituto Internacional de Idiomas, Universidad Pedagógica y Tecnológica de Colombia.

3 Estudió antropología, romanística, ciencia política y ciencias pedagógicas en la Universitá della Calabria (Italia) y en la Justus-Liebig-Universität Gießen (Didaktik der Sozialwissenschaften). Magister Artium (summa cum laude) y Doctor en Filosofía (magna cum laude) en la Justus LiebigUniversität Gießen.

Correo: michele.borrelli@unical.it

Borrelli, M. (2020). La historia de la humanidad interpretada de manera humanista. 


\title{
Resumen
}

Este escrito parte del distanciamiento ante las lecturas idealista y materialista de la historia de la humanidad, para proponer como primera tesis que esta historia debe interpretarse de manera humanista. En este contexto se lleva a cabo un análisis de dos tipos de humanismo: el griego o de la pertenencia, y el moderno o de la emancipación. El primero trata de la pertenencia del hombre a la polis, al cosmos y al marco regulativo de lo considerado como bueno, bello y verdadero, por ejemplo. El segundo resalta los valores de la autonomía, la autodeterminación y la libertad del individuo, que bajo el dominio del mercado cayeron lentamente en un individualismo subjetivista y egoísta, que impide vincular armónicamente pertenencia y emancipación. Se habla entonces de un humanismo del predominio técnico caracterizado por el lucro y el dinero. Este nuevo enfoque marca la ruptura de lo que constituye la segunda tesis de este escrito: emancipación y pertenencia se integran en un humanismo de responsabilidad planetaria, que se configura como contracorriente del nihilismo contemporáneo (tercera y última tesis).

Palabras clave: Humanismo, paideía, pertenencia, emancipación, responsabilidad planetaria, nihilismo.

\begin{abstract}
This writing starts from the distancing of idealistic and materialistic readings of the history of humanity, to propose as a first thesis that this history must be interpreted in a humanistic way. In this context, an analysis of two types of humanism is carried out: Greek humanism or of belonging, and modern humanism or of emancipation. The first deals with man's belonging to the polis, the cosmos, and the regulatory framework of what is considered good, beautiful, and true, for example. The second highlights the values of autonomy, self-determination and freedom of the individual, which slowly fell under the dominion of the market in a subjectivist and selfish individualism, which prevents the harmonious linking of belonging and emancipation. One speaks then of a humanism of technical predominance characterized by profit and money. This new approach marks the rupture of what constitutes the second thesis of this writing: emancipation and belonging are integrated into a humanism of planetary responsibility, which is configured as a countercurrent to contemporary nihilism (third and final thesis).
\end{abstract}

Keywords: Humanism, paideía, belonging, emancipation, planetary responsibility, nihilism. 
Como explicó Marx convincentemente en la undécima tesis sobre Feuerbach (Marx \& Engels, 1948), la historia de la humanidad puede interpretarse de diferentes maneras. Puede interpretarse de manera idealista, como lo hizo Hegel con brillantez y nitidez. También puede ser interpretada de manera dialéctico-materialista, como demostró el mismo Marx -invirtiendo a Hegelcon la misma brillantez y nitidez. Tanto Hegel como Marx han sacado a la luz algo importante, incluso fundamental, sobre la historia humana. Al concepto hegeliano de 'espíritu objetivo' debemos el desarrollo de las humanidades. Al concepto marxista de 'materialismo dialéctico' debemos, por su parte, una nueva antropología, es decir, una nueva interpretación del ser humano: el ser (el trabajo, la estructura económica) se torna aquí central, y no la conciencia (lo pensado o las representaciones que los hombres tienen de sí mismas y del mundo). Pero Marx también añade: no se trata solo de interpretar el mundo, sino de transformarlo. Me interesa el significado, el humanismo de esta transformación.

Todos estamos y seguiremos inmensamente comprometidos con el pensamiento de Hegel y Marx y, sin embargo, cuando se trata de la historia humana (del sentido de la historia humana y del significado del hombre como tal), creo que debemos atrevernos a usar otra categoría.

Mi primera tesis es, por tanto, que la historia de la humanidad no debe interpretarse de manera (solamente) idealista o (exclusivamente) materialista, sino de forma humanista. Por supuesto, esto plantea inmediatamente el ámbito problemático de las siguientes preguntas: ¿qué significa humanista? ¿Qué es el humanismo? ¿Qué es el hombre? ¿Se puede interpretar la historia de una manera humanista? Y ¿de qué imagen del hombre debemos partir en esta interpretación?

No me atrevo a abrir la caja de Pandora acerca del concepto de hombre, acerca de la historia humana. Solo quiero decir, lisa y llanamente, y con modestia, si mi análisis histórico está bien fundado, que Occidente ha producido fundamentalmente dos tipos importantes de humanismo: el humanismo griego (con eso me refiero al humanismo del pensamiento griego), que yo llamo 'humanismo de la pertenencia', y el humanismo de la modernidad, que me gustaría denominar como 'humanismo de la emancipación'. 


\section{Sobre el primer humanismo: sobre el humanismo en el horizonte de la pertenencia}

El primer humanismo se basaba en el presupuesto de la unidad de mito y $\operatorname{logos}$ (racionalidad), y se justificaba en el horizonte normativo de la correspondiente pertenencia, por un lado, a la polis y al cosmos, y, por otro lado, a un marco categorial del indagar conjunto por lo correcto, lo bueno, lo bello, lo verdadero, etc.

El humanismo de nuestros comienzos (y es aquí donde se muestra su grandeza) se difundió también en el doble sentido antropológico de la investigación acerca de cómo el dolor, el sufrimiento, el pesar, la desesperación, la muerte (pensemos en Sócrates) deben ser soportados, y también en la exploración de valores como el coraje, la felicidad, la virtud, el eros (o el amor), sobre todo en la lucha intelectual por la verdad como principal tarea de la filosofía (pensemos, por ejemplo, en Platón). El tan diferenciado 'conócete a ti mismo', en el doble sentido antropológico, plantea la cuestión de la esencia del ser humano, especialmente en su dimensión moral y ética.

Esa esencia, que hace que seamos seres humanos no solo per definitionem (y consecuentemente a priori), sino porque lo seremos realmente en el proceso ad infinitum de la paideía (por autoformación, aposteriori, véase Hegel) u ontológicamente, en el sentido de Aristóteles.

En esta perspectiva antropológica se inaugura de varias formas la dialéctica griega entre el cuidado del cuerpo y el cuidado del alma (de Sócrates a Platón). En el humanismo de la pertenencia, el proceso de tornarse humano no significaba el aislamiento del ser humano al nivel de un individualismo egoísta. La preocupación por uno mismo representaba un concepto ideal concreto con el que se conectaba el espíritu cívico tanto a la conducción de la familia como al gobierno de los asuntos públicos. La suposición era que alguien que no podía cuidarse a sí mismo (especialmente cuidado de su propia alma) tampoco podía ocuparse de los asuntos públicos, es decir, ocuparse de la administración del bien común y no estaba, por tanto, apto para ello.

Con todas estas transiciones del cuidado del cuerpo al cuidado del alma, del cuidado de uno mismo al cuidado del bien común, el horizonte normativo es doble: por un lado, se trata de pertenencia a la comunidad (o polis) y, por otro, de pertenencia al mundo de las cosas (o cosmos). 
En cuanto a la vida en la polis -la ciudad Estado-, las prioridades vinculantes son las normas y leyes de la comunidad. Aquellas normas y aquellas leyes que (mientras sean válidas) sean válidas incondicionalmente a todos los ciudadanos y se apliquen y respeten sin excepción. Prioridades que Sócrates se sintió obligado a respetar, tanto que aceptó su sentencia de muerte, aunque la encontrara injusta e inapropiada.

\section{Sobre el segundo humanismo: Humanismo en el horizonte de la emancipación}

El segundo humanismo, el humanismo moderno, apunta a la emancipación (Ruhloff, 2004) del individuo. También se refiere a un marco normativo, pero ya no al de pertenencia (como valor de la colectividad y de la vida en común), sino a un marco de separación y liberación, cuyos valores fundamentales son la autonomía, la autodeterminación y la libertad del individuo. Estos son valores que la paideía de Occidente, desde la Ilustración en adelante, reconoce y otorga a priori a cada individuo en su calidad de persona.

Valores que en general se extendían cada vez más, probablemente impulsados no solo por el sapere aude de Kant y la Ilustración de Occidente, sino sobre todo bajo el ímpetu desenfrenado de una burguesía ambiciosa y agresiva, que asociaba sus propios intereses con el desarrollo de un mercado cada vez más orientado al capitalismo que influyó en la iniciativa privada, en las inversiones de empresarios individuales y en el libre empresariado. El mercado capitalista vive de la iniciativa del individuo o, mejor aún, de la lucha de los individuos entre sí por el lucro privado. En este sentido, la autonomía y la autodeterminación son categorías que el mercado capitalista dicta independientemente de cualquier Ilustración.

Es así como la desaparición del humanismo de pertenencia va junto con el esploit de un humanismo más radical, con la entronización de una paideía del subjetivismo, que bajo el hilo conductor de la lógica de los mercados se dirige enteramente al tener y no al ser. La pérdida del horizonte común de pertenencia ha sumido el sentido de la tradición y su cultura en una crisis, sin que Occidente pueda sustituirlo por un nuevo horizonte de sentido. A la destrucción de los "viejos" ideales le siguieron la vaciedad de los valores del mercado y una razón que dificulta la reflexión o incluso teme a ésta y, en consecuencia, no tiene el coraje de pensar para evitar llegar a la conclusión de estar aún conectada con el dogmatismo de la metafísica tradicional (Borrelli, 2010). 
La paideía de Occidente no logró unir los dos tipos de humanismo en su tradición (esta es su miseria); los dos tipos de humanismo que de suyo tenían sus buenas razones: la pertenencia a la comunidad y el respeto a la ley no excluyen de hecho la libertad, la autonomía o la autodeterminación del individuo (la emancipación deseada). En una polis responsable la pertenencia y la emancipación pueden hoy convivir y reconciliarse.

La emancipación no es per se un desprendimiento de todo y de todos, sino más bien una garantía que regula (debe regular) los derechos del individuo frente a los derechos de los demás y del propio Estado. La pertenencia a la comunidad prevé las libertades (es decir, la emancipación de la dominación innecesaria) del individuo en la libertad de la comunidad y en la búsqueda del bien común.

La emancipación no tenía y no tiene por qué significar hoy en día necesariamente la ruptura de todos los lazos de pertenencia, y solamente favorecer a un individuo o a los intereses privados de individuos o de grupos. Pero la lógica del interés privado es dominante y, ciertamente, de manera incondicionada. No hubo simbiosis entre el humanismo de pertenencia y el humanismo de emancipación. Los caminos no se cruzaron, se mantuvieron estrictamente en paralelo, para luego (y en última instancia) degenerar en un humanismo singularizado, cuya prioridad es el bienestar del individuo, que de ser necesario deberá hacerse cumplir por todos los medios posibles aun en detrimento de la comunidad.

Teniendo en cuenta esta reducción destructiva de los potenciales presentes en las dos formas del humanismo de Occidente, ciertamente se puede hablar de la grandeza, pero también de la miseria de nuestra paideía, si entendemos ésta no solo como educación en las escuelas (asumiendo que ella existe allí), sino también como la cultura y el ideario de Occidente en general.

La emancipación no es per se un concepto que contradiga al humanismo de la physis. Es precisamente la physis, la idea ontológica, la que permite que las cosas sean como son. Para la physis, todo ser es él mismo y para ser él mismo debe tener la oportunidad de explicarse tal cual es en su esencia (o a su manera), y esto es válido ( $\mathrm{y}$ debe valer) tanto para el ser general como para el ser en particular. El ser no puede ser subyugado por ningún otro ser.

Por tanto, physis y emancipación no son conceptos contradictorios. El ser, relacionado con el ser humano, puede ser un ser real si es ser por sí mismo. En 
otras palabras: la idea del ser humano en su autonomía y autodeterminación no es per se lo contrario de la idea de la la physis del humanismo de nuestros inicios.

Si aceptamos la idea de la physis como idea reguladora del ser social, nos percatamos de que la emancipación, que sólo se entiende como desapego, y no como pertenencia (a la sociedad, al mundo, al cosmos), se convierte en un problema. Liberada de todo y de todos, la idea de emancipación se transforma en lo contrario de la physis: el 'ser uno mismo' prevalece sobre el interés de la comunidad, el interés privado sobre el interés público (o bien común).

En el mismo momento en que esto sucedió (y sigue sucediendo) nos hemos despedido (y nos estamos despidiendo) del humanismo de nuestros inicios. El humanismo de la emancipación de la modernidad es una prueba clara e inconfundible de este proceso de ruptura radical con el humanismo de pertenencia.

Mi segunda tesis reza así: pertenencia y emancipación se incluyen mutuamente y conducen al humanismo de la responsabilidad planetaria. El humanismo de la emancipación se opuso al humanismo de la pertenencia no solo como modelo cultural, sino también, y ante todo, como modelo económico. La libre empresa para el libre mercado ha desvanecido la noción del bien común, o del bien en sí mismo (del agathon); la noción que formó la grandiosidad de la paideía de los albores de Occidente.

Las leyes del mercado, completamente abandonadas a sus propios dispositivos, y bajo el control de los procesos más salvajes y no regulados, han hecho y están haciendo cumplir la anarquía tanto a nivel estrictamente económico como a nivel cultural, profanando y desmitificando toda la tradición de las ideas de los albores como si ésta fuera una mera tradición de inconvenientes y oscurantismo (Horkheimer y Adorno, 1974, p. 20).

De hecho, la modernidad no solo se ha opuesto injusta e incorrectamente al legado de ese gran ideario y esa gran tradición cultural, sino que también ha transformado gradualmente el humanismo de la emancipación en un humanismo aún más estricto y radical: en el humanismo del dominio técnico con sus más importantes consecuencias, como la ganancia, el lucro y el dinero.

¿Qué humanismo se afirma ahora? El humanismo individualista, es decir, un concepto de emancipación como autonomía del individuo, libertad del 
individuo, disfrute del individuo, riqueza del individuo, vida del individuo (Horkheimer, 1969, p. 113). No fue el iluminismo de Kant, sino el humanismo del pensar en sí mismo lo que prevaleció. No es sorprendente, entonces, que en la cultura de la emancipación individualista, la autoafirmación y la autorrealización tengan prioridad sobre los intereses y necesidades comunales y la humanidad en general. Esto también explica por qué ahora en el mundo contemporáneo no sólo existen aquellos que mueren de hambre, sino también aquellos que mueren por haber comido demasiado.

Y la paideía (no solo la que existe en la cultura global general, sino también aquella que se limita a los salones escolares, o aquella que está expuesta en las hegemonías sociales particulares) apoya este escándalo de desigualdad total, promoviendo el concepto de emancipación individualista y singularizada como motor del progreso social. En esta situación no cabe duda de que las leyes del mercado del Occidente capitalista han logrado llegar a todas las áreas espirituales de su paideía integral.

Ahora todo tiene que partir de la iniciativa del individuo, todo se desarrolla en torno a la iniciativa individual y se justifica por un interés individualizado, mientras el Estado, observador solitario y mudo, no debe interferir en la libertad de quien toma y ofrece más, de quien explota mejor y acumula más, de quien no da nada y lo roba todo. Sin embargo, el sentido original de la libertad del humanismo en Occidente no significa en absoluto tomar todo y no dejar nada para los demás. Algo completamente diferente es cierto: Occidente habló y sigue hablando enfáticamente de la dignidad humana en el sentido universal. La dignidad de todos era y sigue siendo de hecho un imperativo. Para Kant racionalidad y moralidad, ciertamente, no son sinónimos por casualidad y, en consecuencia, coinciden a priori.

Después del colapso del sentido de pertenencia como horizonte colectivo en el que se podía conocer, y con el cual el hombre podía identificarse, la reivindicación de la emancipación del individuo se transformó potencialmente en motivo para la guerra de unos contra otros por el bienestar del individuo y no por bienestar de todos. Una prueba clara de esta lógica de las armas se puede ver en el daño que muchas veces la libre empresa causa sin impedimento alguno al medio ambiente. Guiados por el interés del lucro, destruyen, si es necesario en nombre del dios del lucro, el territorio, el espacio vital de todos.

Territorio común vinculado a los derechos que las generaciones futuras también deben exigir y poder reclamar. Fragmentado y singularizado, el 
humanismo de la emancipación no es un horizonte en el que el individuo y la colectividad se reconozcan como una totalidad que lucha por el bien común. El bien común, por otro lado, corre el riesgo de convertirse en una miseria común. La pregunta es: ¿de qué debería emanciparse la comunidad (o la humanidad) en su conjunto? ¿Seguramente no de si mismo? ¿De la naturaleza? "No podemos emanciparnos de la naturaleza" (Spämann, 1987). La humanidad debe a la naturaleza todas sus posibilidades de existir. Por decirlo con prudencia, es una paradoja que haya surgido una ruptura tan profunda entre el humanismo de pertenencia y el humanismo de emancipación, de tal manera que haya creado paradigmas antitéticos.

Pertenencia y emancipación son épocas fundamentales de la paideía de Occidente, épocas significativas que no merecieron y no merecen esta guerra fratricida. Más que una exclusión mutua, estos dos paradigmas deben gozar del reconocimiento mutuo en una relación de integración y colaboración. La emancipación, cualquiera que sea su definición, presupone de hecho un marco de pertenencia.

Incluso en su singularidad, el hombre no puede emanciparse de todo y de todos. Necesita a los demás si quiere ser él mismo. Aristóteles habló correctamente de zoon politikon (Aristóteles, 1988; 1993) y entendió con esto la pertenencia del hombre a la comunidad o polis; pertenencia, per definitionem. Sin un marco de pertenencia dejarían de existir también las formas de convivencia comunitaria, dentro de las cuales puede hablarse de emancipación en singular, en el sentido de la paideía de nuestro segundo humanismo; una emancipación que este último humanismo cree (erróneamente) que puede avanzar imperturbablemente rompiendo todos los lazos.

De hecho son las formas de la vida organizada en común las que garantizan las diferencias y peculiaridades individuales. Sin embargo, estas formas requieren en su interior un punto de referencia común, un acuerdo sobre reglas y principios: una ética mínima. Basándome en la idea de una ética mínima global necesaria, considero que es posible afirmar que no hay paideía sin pertenencia y tampoco hay emancipación que pueda eludir a esta última e, independientemente de ésta, reclamar un sentido con vigencia universal.

La tercera tesis puede sintetizarse sosteniendo que el humanismo de la responsabilidad planetaria es la respuesta al nihilismo. En lugar de cultivar este espacio común de encuentro, el segundo humanismo de la paideía de Occidente se sometió al largo camino de la anarquía propia de la racionalidad técnica, con el riesgo de convertirse en su medio y su fin. 
El segundo humanismo (en la transformación en tecnología) también ha quemado las últimas condiciones de su esencia: con esencia me refiero a la unidad de mythos y logos (razón) del primer humanismo. Lo decible y lo indecible no eran (y todavía no son) polos que se excluyen a sí mismos, sino que formaron y siguen formando un concepto de razón de gran alcance (de una razón problemática, en el sentido de Vico y no solo de Vico) (1847), que es capaz de satisfacer no solo las necesidades técnicas y materiales de la vida, sino también de preservar la totalidad de las necesidades espirituales del hombre en su integridad y amplitud. En este sentido amplio, el mito es una parte esencial de la razón, y lo es incluso allí donde la razón escapa a éste, donde es incompleta y abreviada.

La ilustración racionalista de Occidente, que se extiende íntegramente a la desmitización y profanación de la tradición, favoreció la puesta en práctica de una concepción técnica del progreso y, en consecuencia, renunció a su identidad, que ciertamente no era solo la cuestión de lo útil (individualizado), sino también la cuestión de lo bello y, lo que es más importante, la del bien común.

No satisfecha con eso, la ciencia técnica del segundo humanismo impuso la idea de una paideía sin sentimiento, sin corazón, sin empatía. El fin último de esta paideía se resume en la expresión: razón calculadora, un modelo que Horkheimer y Adorno definieron como razón instrumental y lo han separado del modelo reflexivo de la razón (Horkheimer, 1969).

En efecto, en el humanismo moderno se desvaneció el pensamiento reflexivo; la forma de pensamiento que evidentemente no niega lo útil, sino que lo integra en las esferas simbólicas y normativas de la vida comunitaria. Estas últimas son esferas que el hombre ha incorporado en sí y que configuran su antropología más profunda. En consecuencia, el hombre técnico no debe oponerse al hombre simbólico (Cassirer, 1961).

Hay aún otra autoridad que no debe omitirse, sin embargo, en el sentido antropológico que es esencial aquí: el hombre ético. Y, de hecho, la orientación hacia normas, principios y reglas siempre ha sido un requisito fundamental de la historia de la humanidad occidental y de cada uno de sus progresos posteriores. El progreso mismo, como concepto, remite a una idea ética (desde Sócrates, pasando por Aristóteles, a Hegel y Apel), a un horizonte y a una idea regulativa (Kant) que fue considerada como una medida, como una guía en la historia humana, y no precisamente en la historia de la tecnología. 
Y si una idea de comunidad (tanto a nivel local como global) es impensable sin un mínimo acuerdo sobre los principios que regulan la convivencia, se comprende aún menos cómo en Occidente la razón instrumental pudo asumir esa superioridad sobre la razón reflexiva. Pascal señaló el hecho de que también es posible pensar de manera diferente, insistiendo en la razón del corazón como el camino ulterior de acceso a la realidad humana, partiendo así del supuesto de que el corazón posee una razón que no conoce la razón (ratio). El propio Kant hizo la brillante, aunque quizás problemática, distinción entre razón teórica, práctica y estética. La razón técnica, como la hemos experimentado y la seguimos experimentando en su dominio absoluto, no es necesariamente una ley de la historia humana.

El pensamiento occidental, pensamiento que originalmente vivió de la conexión indisoluble entre mythos y logos, ha prescindido del componente (quizás) más importante de su paideía: el mythos (sentimientos, emociones, creatividad, arte), el eros, el bienestar de todos y de las cosas. Quizás esto explique la otra razón por la cual Occidente ha creado un nuevo mito, ya que no pudo ni puede llenar el vacío que este componente vital dejó y sigue dejando en el hombre: reemplazó la destrucción del mito por el mito de la destrucción (Borrelli, 2000, pp. 50-69).

\section{Conclusión: nuevo humanismo o nihilismo: la paideía del humanismo de la responsabilidad como retorno al ser}

¿Cómo se puede responder a una antropología que contra su voluntad corre el riesgo del nihilismo? ¿Se puede volver de 'una paideía del tener' a una nueva 'paideía del ser' todavía posible? Para quienes se orientan hacia esta última, es obvio que hay que redefinir nuestra actual situación histórica y luego repensarla nuevamente de manera radical. Tendríamos que volver a invertir nuestra antropología (ya invertida) según la fórmula que Hegel (1986) y Marx (2018) denominaron 'dialéctica de la negación de la negación'. Las condiciones para la inversión de una realidad invertida, o la transición del ser al tener y un nuevo retorno al ser (inversión de la inversión) no son fáciles, sino que todo depende de la construcción de un nuevo humanismo, del deseo de abrirse a una nueva concepción del hombre; lo que significa un retorno al ser.

Pero el regreso al ser no es el acontecimiento del que habla Heidegger. El hombre no puede vivir a la espera de un acontecimiento que pueda ocurrir o no, como piensa Heidegger. No se retorna al ser apelando a un 
acontecimiento que es él mismo y en el que se puede participar solamente a modo de escucha. El ser del humanismo futuro no podrá estar fuera del hombre en lo que respecta a su posibilidad e historicidad. Este ser no es producido por iniciativa propia (independiente de las decisiones del hombre) como piensa Heidegger. No está guiado por algún poder misterioso o por el hado de la historia. Si consideramos adecuado orientarnos hacia la escucha del ser, nos encontramos ya ante el ser que somos nosotros mismos y ante la responsabilidad que nosotros mismos representamos y que nunca debe delegarse a un destino fuera de nosotros.

El ser que postulamos no es un acontecimiento que pueda venir de sorpresa y sucedernos sin que nosotros lo sepamos, y que guíe nuestros destinos sin nuestro consentimiento, sino que es ese encuentro de pertenencia y emancipación que ha separado épocas de nuestra paideía, y en el que ahora depende de nosotros consolidar este ser nuevamente con rigor en el signo del horizonte normativo del humanismo de responsabilidad planetaria. El ser como encuentro dialéctico que sirve para pensar nuevamente acerca de la humanidad (en su diversidad y singularidad). 'Ser' como una nueva percepción del mundo y de nosotros mismos.

Una percepción que toma posesión del ser bajo la guía de la responsabilidad. Todo ser humano pertenece al ser (de sí mismo) y al ser (de lo común) que es la humanidad. Si este es el horizonte compartido, en parte es como retroceder al tiempo en que existían la belleza y el asombro, y los seres humanos percibían la maravilla de la existencia de las cosas. Escalar de nuevo al asombro que estaba relacionado con la pregunta: ¿qué es el ser? Retornar con el pensamiento que se remonta al tiempo atrás, en el que se preguntaba por el fundamento de este ser y se buscaba sus causas y principios. Uno estaba asombrado y fascinado por la infinidad de la totalidad. En este sentido, un nuevo humanismo es también un humanismo viejo, incluso antiguo; humanismo auroral.

Un humanismo en el que la representación de la vida, y una buena vida bajo el signo de ese asombro original, significa pertenencia a las cosas y no emancipación o desapego de todo debido a una autarquía individualista de uno contra otro. Una vida que nos retrotrae lejos en el tiempo a la idea original de physis, un concepto que, en contraste con el subsiguiente concepto de naturaleza, conserva intacta la autenticidad del ser (cada ser); concepto que permite que el ser (es decir, el ser de todos y de todas las cosas) permanezca en su constitución y esencia de lo que es (y lo es) y, por ende, en su unicidad, si queremos, también original y siempre actual. 
Un humanismo no inspirado en la nada nihilista, sino en la concepción reguladora de la vida y el buen vivir como derecho del ser de los pueblos y, por tanto, del ser (o existencia) de cada uno de nosotros. La buena vida no es un derecho de unos pocos, sino el concepto regulador que debe guiar a la humanidad en su continuo e infinito camino de humanización.

Pero cada trayecto de la humanidad tiene lugar en el espacio de la casa común que representa la tierra con sus muchos lugares reales, sus muchas historias, sus muchos idiomas y sus muchas contradicciones y conflictos. Es deber del nuevo humanismo de la responsabilidad llevar adelante la dialéctica de la diversidad en la unidad (Apel y Borrelli, 2011) de lo común para el bien de todos.

Orientarse hacia este nuevo humanismo significa un nuevo replanteamiento en el que el humanismo de la pertenencia y el humanismo de la emancipación se reencuentran bajo el signo del nuevo pensamiento (responsable) sobre nosotros y las cosas. Nuevamente: reflexionar significa volver a pensar, retornar al ser como una responsabilidad planetaria. El pensar que no es solo 'ser' heideggeriano que se abre en anonimato.

Es el pensar que por el contrario significa reflexión (Nachdenklichkeit) en el marco de la responsabilidad para con nosotros mismos y con las cosas. Un pensamiento que hemos perdido durante siglos con la imposición del 'tener' sobre la esencia original del 'ser' (de todas las cosas). Una esencia que es también moralidad si pensamos que la vida y el buen vivir son categorías éticas y no el 'nada biológico' físico del mero vivir al día en convivencia e incluso en detrimento del otro.

Volver a apropiarse (aneignen) del com-partir (Mit-Teilen), de la com-pasión (Mit-Leiden), de la co-responsabilidad (Mit-Verantwortung) es un imperativo ineludible. El retorno al pensar significa la vuelta al ser responsable (y no al misterio de un ser en sí). Del doble concepto de conocimientoresponsabilidad proviene el objetivo de poder-pensar. Incluso decimos que éste es el imperativo para el humanismo de la paideía del futuro (Apel, 2014). Poder-pensar, reflexionar responsablemente sobre la vida, el sentido de la vida, sobre lo que importa en la propia vida y en la vida de los demás, son las tareas de la paideía como revolución antropológica en la forma de pensar pedagógica, es decir, en las escuelas y en general en la sociedad de todo el mundo contemporáneo. 
Imaginar la paideía en términos de sabiduría y no solo como una acumulación de conocimientos, tiene como objetivo reflexionar en torno a la propia vida y acerca del sentido que se quiere dar a la propia existencia. Todo ello invita a una reflexión que emprende y debe emprender sobre sí misma la autoconciencia individual y colectiva, al repensar el propio horizonte ético, los propios deseos, el propio estado de ánimo, la emocionalidad etc.; reflexión que nos impulsa (individual y colectivamente) a amar u odiar y actuar de una o de otra forma.

Una paideía también de la pasión y del corazón. Estos son precisamente dos términos esenciales que nos conectan con el otro y con nosotros mismos (y nos conectan a cada uno de nosotros por todo el mundo), y en ausencia de los cuales se cae en la indiferencia y la apatía, así como también en el desánimo y el abandono de la búsqueda de una mejor vida para nosotros y para los demás (Galimberti, 2013).

El camino opuesto a esta nueva paideía (este nuevo humanismo del hombre completo), a este regreso al 'ser' en el doble sentido antes mencionado (relativo a nosotros y a las cosas), a esta revolución en la forma de pensar pedagógica y socialmente, es el vacío insensible y lúgubre de la falta de sentido. En última instancia, la alternativa a la paideía planetaria del humanismo de la responsabilidad es la reintroducción del principio del homo homini lupus, "el hombre es un lobo para el hombre" (Hobbes, 2008). En otras palabras: la alternativa es comerse unos a otros por la propia supervivencia, la pérdida de todos los valores, de todos los horizontes normativos, de cada dios (Nietzsche) como idea reguladora: la alternativa es el nihilismo (Borelli, 2017).

\section{Referencias}

Apel, K. O.; Borrelli, M.; Fornet-Betancourt, R. e Panikkar, R. (2011). L'intercultura: Filosofia e pedagogia. Cosenza: Pellegrini.

Apel, K. O.; Borrelli, M.; Burkhart, H.; Colombo, A.; Cortina, A. e FornetBetancourt, R. (2014). La fondazione dell'etica e la responsabilità per il futuro. Cosenza: Pellegrini.

Aristóteles (1988). Politica. (Trad. Garcia, M.). Madrid: Gredos.

Aristoteles (1993). Ética Nicomaquea. (Trad. Pallí Bonet, J.). Madrid: Gredos. 
Borrelli, M. (2010). Postmodernità e fine della ragio. Cosenza: Pellegrini.

Borrelli, M. (2017). Nuovo umanesimo o nichilismo - Grandezza e miseria dell'Occidente. Trieste: Asterios.

Cassirer, E. (1961). Filosofia delle forme simboliche. Firenze: La Nuova Italia.

Galimberti, U. (2013). L'ospite inquietante. Il nichilismo e i giovani. Milano: Feltrinelli.

Hegel, F. (1986). Phänomenologie des Geistes. Moldenhauer, E. und Michel, K. (Hrsg.). Frankfurt a. M.: Suhrkamp.

Helmer, K.; Meder, N.; Drawe, K. M. und Vogel, P. (Hrsg.). (2000). Spielräume der Vernunft - Jörg Ruhloff zum 60. Geburtstag. Von der Zerstörung des Mythos zum Mythos der Zerstörung, (pp. 50-69). Würzburg: Königshausen und Neumann.

Hobbes, Th. (2008). Leviathan. Gaskin, J. (Ed.). UK: Oxford University Press.

Horkheimer, M. (1969). Eclissi della ragione. Turin: Einaudi.

Horkheimer, M. \& Adorno, Th. W. (1974). Dialettica dell'illuminismo. Turin: Einaudi.

Marx, K. und Engels, F. (1948). Ludwig Feuerbach und der Ausgang der klassischen deutschen Philosophie. Hajek, H. (Hrsg.). Leipzig: Meiner Verlag.

Marx, K. (2018). Das Kapital. Engels, F. (Hrsg.). Hamburg. Severus Verlag.

Spämann, R. (1987). Das Natürliche und das Vernünftige. Aufsätze zur Anthropologie. München: Piper Verlag.

Ruhloff, J. (2004). „Emanzipation”. Historisches Wörterbuch der Pädagogik. Benner, D. und Oelkers, J. (Hrsg.). Weinheim / Basilea: Beltz Verlag.

Vico, G. (1847). Principi di Scienza Nuova. Firenze: Tipografia di Alcide parenti. 